\title{
Prescribing Aducanumab in the Face of Meager Efficacy and Real Risks
}

David S. Knopman, MD, and Joel S. Perlmutter, MD

Neurology ${ }^{\circledR}$ 2021;97:545-547. doi:10.1212/WNL.0000000000012452

The US Food and Drug Administration (FDA) approved aducanumab on June 7, 2021, using an accelerated approval mechanism, based on evidence that aducanumab reduced brain $\beta$-amyloid $(\mathrm{A} \beta)$ peptide. ${ }^{1}$ The FDA press release stated that the effect on the surrogate end point "is reasonably likely to predict a clinical benefit to patients..." at some point in the future. As clinical neurologists, we should understand the evidence for this approval and whether this justifies prescribing this medication.

The saga of aducanumab's journey is convoluted..$^{2-4}$ Two phase III studies were initiated in August 2015. They were constructed and executed in an identical manner. In March 2017, the sponsor revised the protocol to allow all participants assigned to the high-dose arm to receive $10 \mathrm{mg} / \mathrm{kg}$. The sponsor conducted a preplanned futility analysis, which led to termination of both studies in March 2019. Three months later, in a surprise press release, the company stated that subsequent analyses with another 3 months of data led them to conclude that there was a sufficient clinical efficacy signal to pursue a new drug application. In follow-up post hoc analyses conducted by the sponsor, one trial (EMERGE or 302) showed statistically significant effects in the high-dose group on several clinical outcome measures; the other study (ENGAGE or 301) showed no benefits. ${ }^{2,3,5,6}$

We as neurologists need a strategy to advise our patients in this unusual situation where the drug was approved without evidence of consistent clinical benefits. Based on the prescribing information, ${ }^{7}$ the sponsor shows data from only the positive trial and fails to provide the negative trial's cognitive and functional outcomes. Neurologists should have access to all of the relevant data in these clinical trials; however, they will have to go elsewhere to find it. ${ }^{2,3,5,6}$ Even choosing to focus on the one trial with the favorable outcome in the high-dose group and ignoring the negative trial, the clinical benefits are decidedly small. The drug never produced substantial improvements. The clinical benefit amounted to about 3 months' worth of delay in decline over a year (annualized Clinical Dementia Rating Scale sum of boxes 0.26 rating points reduction in decline with high-dose aducanumab in the setting of 1.17 points annualized decline in the placebo group). Because our field has not established what constitutes clinical meaningfulness, this benefit could be perceived as having value by some patients and their families. However, this range of delay and progression is well within the untreated variability of groups of patients with mild cognitive impairment $(\mathrm{MCI})$ or dementia due to Alzheimer disease $(\mathrm{AD}){ }^{8}$. The negative trial, which cannot be brushed under the rug, raises questions about the reliability and reproducibility of any such claimed benefits. The sponsor's presentation at the FDA hearing on November 6, 2020, proposed several post hoc explanations to account for the negative results; however, subjecting the positive trial to post hoc analyses introduced substantial bias and raised serious questions about dose effects and effects on subgroups, as pointed out by the FDA's statistician. ${ }^{9}$ Combining the results from the 2 trials found no statistically significant clinical benefit for high-dose aducanumab. ${ }^{6}$ As part of this accelerated approval, the FDA requires Biogen to conduct another prospective clinical trial over the next 9 years to determine whether this drug produces clinical benefit.

The FDA focused on an alternative outcome measure to justify accelerated approval of aducanumab. Rather than relying on a failed clinical end point, the FDA pointed out that the drug lowered brain $A \beta$, using this biomarker as a surrogate end point. A surrogate outcome measure is reasonable if it predicts clinical benefit. However, no data from either trial or any other source indicate that lowering

\author{
Correspondence \\ Dr. Knopman \\ knopman@mayo.edu
}

RELATED ARTICLES

Editorial

Clinical Efficacy, Drug

Safety, and Surrogate

Endpoints: Has

Aducanumab Met All of Its Expectations?

Page 517

\section{Viewpoint}

Aducanumab, Amyloid

Lowering, and Slowing of

Alzheimer Disease

Page 543

From the Department of Neurology (D.S.K.), Mayo Clinic, Rochester, MN; and Department of Neurology (J.S.P.), Washington University School of Medicine, St. Louis, MO.

Go to Neurology.org/N for full disclosures. Funding information and disclosures deemed relevant by the authors, if any, are provided at the end of the article. 
brain $\mathrm{A} \beta$ provides clinical benefit to individuals with $\mathrm{AD}$ or when such benefit would occur, if it does. In fact, over the 18-month clinical trials with aducanumab, the FDA explicitly acknowledged no consistent clinical benefit occurred. Several studies demonstrated that lowering $A \beta$ in the brain by inhibition of $\beta$ - or $\gamma$-secretases made patients cognitively worse. ${ }^{10}$ Furthermore, the change in cognitive performance with aducanumab in the two phase 3 trials did not correlate with the reductions in brain $A \beta$, as analyzed the FDA's own statistician. In the cardiovascular world, there are many examples of claims based on "sure-thing" biomarker changes that failed to predict eventual clinical benefits. ${ }^{11}$ Nevertheless, without evidence, lowering $A \beta$ can only hope to be disease-modifying.

Neurologists must also consider the risks, especially in light of the low potential for benefit. Patients with an excess of cortical microbleeds and those on most anticoagulants should not receive aducanumab. Infusion of the recommended monthly doses of aducanumab comes with safety concerns, especially in the form of amyloid-related imaging abnormalities_edema or hemorrhage. With a rate of $40 \%$, and higher in APOE $\varepsilon 4$ carriers, ${ }^{5}$ safety monitoring must be integrated into management. Patients must be able to undergo MRI scans and APOE genotyping for safety reasons. Skilled neuroradiology is also a necessity.

With the above caveats, neurologists then need to determine which patients may be appropriate for aducanumab. With the above caveats, neurologists then need to determine which patients may be appropriate for aducanumab. The original prescribing information ${ }^{7}$ was revised by the sponsor with approval by the FDA on July 8, 2021 from an apparently very broad indication of "Alzheimer's disease" to a much smaller group of "patients with mild cognitive impairment and mild dementia... the population in which treatment was initiated in clinical trials." ${ }^{2}$ The sponsor acknowledged that there is no evidence for treating patients with aducanumab who are either milder than mild cognitive impairment or more impaired than mild dementia, nor is there safety information in those groups. The revised approved indication guides neurologists to avoid prescribing aducanumab to more severely affected patients. There is no evidence for treating patients whose cognitive disorder is jointly attributed to $\mathrm{AD}$ and another etiology. Because aducanumab's target is elevated brain $A \beta$, neurologists must have the available technology to verify that a candidate for aducanumab has elevated brain $A \beta$. Clinical diagnoses alone are insufficient to verify elevated $A \beta$.

Aducanumab's approval raises expectations for treatments for patients with symptomatic $\mathrm{AD}$. On the one hand, neurologists want to offer hope. Yet, aducanumab's benefits are meager, if even present, ${ }^{13}$ and there are nontrivial risks of side effects. These issues place a substantial burden on neurologists to take the time and effort to counsel patients and families on expectations for aducanumab treatment. Neurologists will have to manage therapeutic perceptions by presenting patients and families with unbiased information about the benefits and risks. This is even more challenging as no peer-reviewed publication is available.

\section{Study Funding}

The authors report no targeted funding.

\section{Disclosure}

D.S. Knopman serves on a Data Safety Monitoring Board for the DIAN study; serves on a Data Safety Monitoring Board for a tau therapeutic for Biogen but receives no personal compensation; is an investigator in clinical trials sponsored by Biogen, Lilly Pharmaceuticals, and the University of Southern California; has served as a consultant for Roche, Samus Therapeutics, Third Rock, and Alzeca Biosciences but receives no personal compensation; and receives funding from the NIH. J.S. Perlmutter has received research funding from the NIH (NS075321, NS103957, NS107281, NS092865, U10NS077384, NS097437, U54NS116025, U19 NS110456, AG050263, AG-64937, NS097799, NS075527, ES029524, NS109487, R61 AT010753 [NCATS, NINDS, NIA], RO1NS118146, R01AG065214), Department of Defense (DOD W81XWH-217-1-0393), Michael J Fox Foundation, Barnes-Jewish Hospital Foundation (Elliot Stein Family Fund and Parkinson disease research fund), American Parkinson Disease Association (APDA) Advanced Research Center at Washington University, Greater St. Louis Chapter of the APDA, Paula and Rodger Riney Fund, Jo Oertli Fund, Huntington Disease Society of America, Murphy Fund, and CHDI; has received honoraria from CHDI, Huntington Disease Study Group, Parkinson Study Group, Beth Israel Hospital (Harvard group), University of Pennsylvania, and Stanford University; is co-director for the Dystonia Coalition, which has received the majority of its support through the NIH (grants NS116025, NS065701 from the National Institutes of Neurological Disorders and Stroke and TR 001456 from the Office of Rare Diseases Research at the National Center for Advancing Translational Sciences); serves as Director of Medical and Scientific Advisory Committee of the Dystonia Medical Research Foundation, Chair of the Scientific Advisory Committee of the Parkinson Study Group, Chair of the Standards Committee of the Huntington Study Group, member of the Scientific Advisory Board of the APDA, Chair of the Scientific and Publication Committee for ENROLL-HD, and member of the Education Committee of the Huntington Study Group; and has provided medical legal consultation to Wood, Cooper and Peterson, LLC, and Simmons and Simmons LLP. D.S. Knopman and J.S. Perlmutter were members of the Peripheral and Central Nervous System Advisory Committee of the Food and Drug Administration but resigned on June 7 and 9, respectively. J.S. Perlmutter participated in the Advisory Committee meeting of November 6, 2020, but D.S. Knopman had been recused from that meeting because he was a site investigator in the aducanumab ENGAGE study. Go to Neurology.org/N for full disclosures.

\section{Publication History}

Received by Neurology June 16, 2021. Accepted in final form June 22, 2021. 
Appendix Authors

\begin{tabular}{lll}
\hline $\begin{array}{l}\text { Authors } \\
\begin{array}{l}\text { David S. } \\
\text { Knopman, } \\
\text { MD }\end{array}\end{array}$ & $\begin{array}{l}\text { Mayo Clinic, } \\
\text { Rochester, MN }\end{array}$ & $\begin{array}{l}\text { Drafting/revision of the manuscript } \\
\text { for content, including medical writing } \\
\text { for content }\end{array}$ \\
\hline $\begin{array}{l}\text { Joel S. } \\
\text { Perlmutter, } \\
\text { MD }\end{array}$ & $\begin{array}{l}\text { Washington } \\
\text { Medicine }\end{array}$ & $\begin{array}{l}\text { Drafting/revision of the manuscript } \\
\text { for content, including medical writing } \\
\text { for content }\end{array}$ \\
\hline
\end{tabular}

\section{References}

1. US Food and Drug Administration. FDA grants accelerated approval for Alzheimer's drug. 2021. Accessed. June 7, 2021. fda.gov/news-events/press-announcements/fdagrants-accelerated-approval-alzheimers-drug

2. Knopman DS, Jones DT, Greicius MD. Failure to demonstrate efficacy of aducanumab: an analysis of the EMERGE and ENGAGE trials as reported by Biogen, December 2019. Alzheimers Dement. 2021;17(4):696-701.

3. Kuller LH, Lopez OL. ENGAGE and EMERGE: truth and consequences? Alzheimers Dement. 2021;17(4):692-695.
4. Cummings J, Aisen P, Lemere C, et al. Aducanumab produced a clinically meaningful benefit in association with amyloid lowering. Alzheimers Res Ther. 2021;13(1):98.

5. EMERGE and ENGAGE Topline Results: Two Phase 3 Studies to Evaluate Aducanumab in Patients with Early Alzheimer's Disease. 2019. Accessed December 8, 2019. investors. biogen.com/static-files/ddd45672-9c7e-4c99-8a06-3b557697c06f

6. Lin GA, Whittington MD, Synnott PG, et al. Aducanumab for Alzheimer's Disease: Effectiveness and Value; Draft Evidence Report. Institute for Clinical and Economic Review; 2021. Accessed. June 2, 2021. icer.org/assessment/alzheimers-disease-2021/

7. Biogen. Prescribing information for Aduhelm. 2021. Accessed. June 7, 2021. accessdata.fda.gov/drugsatfda_docs/label/2021/761178s000lbl.pdf.

8. Jutten RJ, Sikkes SAM, Van der Flier WM, et al. Finding treatment effects in Alzheimer trials in the face of disease progression heterogeneity. Neurology. 2021;96: e2673-e2684

9. Massie T, BLA 761178 statistical review: aducanumab in Alzheimer's. 2020. Accessed. June 15, 2021. collaboration.fda.gov/pradgevcxis7.

10. Egan MF, Kost J, Voss T, et al.. Randomized trial of verubecestat for prodromal Alzheimer's disease. N Engl J Med. 2019;380(15):1408-1420.

11. Echt DS, Liebson PR, Mitchell LB, et al. Mortality and morbidity in patients receiving encainide, flecainide, or placebo: The Cardiac Arrhythmia Suppression Trial. N Engl J Med. 1991;324(12):781-788.

12. Biogen. FDA Approves Updated ADUHELM Prescribing Information to Emphasize Population Studied in Clinical Trials. Accessed July 8, 2021. https://investors.biogen. $\mathrm{com} /$ news-releases/news-release-details/fda-approves-updated-aduhelmtm-prescribing-information-emphasize

13. Liu KY, Schneider LS, Howard R. The need to show minimum clinically important differences in Alzheimer's disease trials. Lancet Psychiatry. Epub 2021 Jun 1.

\section{Did You Know...}

... you can browse by subspecialty topics on Neurology.org?

Go to: Neurology.org and click on "Topics" in the top navigation bar.

\section{Access the 2021 Annual Meeting Anytime, Anywhere}

Access $300+$ hours of content, 140+ programs with syllabi, 25+ exclusive bonus presentations, and integrated CME testing-anytime and anywhere through March 31, 2022-with 2021 Annual Meeting On Demand! Visit AAN.com/AMOD to order yours today.

\section{Get NeuroReady!}

Preparing for the neurology boards? Up for recertification? Looking for a solid foundational knowledge in neurology? Get ready with the AAN's convenient online courses-NeuroReady: Board Prep Edition or NeuroReady: Continuing Certification Edition, and the new NeuroReady: Advanced Practice Provider Edition. Includes 12 months of access. Get ready to review, self-assess, and succeed at AAN.com/NeuroReady. 


\section{Neurology}

\section{Prescribing Aducanumab in the Face of Meager Efficacy and Real Risks}

David S. Knopman and Joel S. Perlmutter

Neurology 2021;97;545-547 Published Online before print July 7, 2021

DOI 10.1212/WNL.0000000000012452

This information is current as of July 7, 2021

\section{Updated Information \& Services}

\section{References}

Citations

Subspecialty Collections

Permissions \& Licensing

Reprints including high resolution figures, can be found at: http://n.neurology.org/content/97/11/545.full

This article cites 6 articles, 1 of which you can access for free at: http://n.neurology.org/content/97/11/545.full\#ref-list-1

This article has been cited by 3 HighWire-hosted articles: http://n.neurology.org/content/97/11/545.full\#\#otherarticles

This article, along with others on similar topics, appears in the following collection(s):

All Cognitive Disorders/Dementia

http://n.neurology.org/cgi/collection/all_cognitive_disorders_dementia Alzheimer's disease

http://n.neurology.org/cgi/collection/alzheimers_disease

MCI (mild cognitive impairment)

http://n.neurology.org/cgi/collection/mci_mild_cognitive_impairment

Information about reproducing this article in parts (figures,tables) or in its entirety can be found online at:

http://www.neurology.org/about/about_the_journal\#permissions

Information about ordering reprints can be found online:

http://n.neurology.org/subscribers/advertise

Neurology ${ }^{\circledR}$ is the official journal of the American Academy of Neurology. Published continuously since 1951, it is now a weekly with 48 issues per year. Copyright (C 2021 American Academy of Neurology. All rights reserved. Print ISSN: 0028-3878. Online ISSN: 1526-632X.

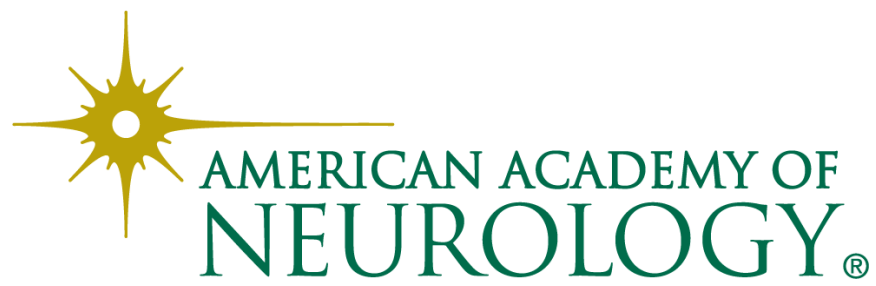

